\title{
POTENSI PERAN FARMASIS DALAM MENINGKATKAN KUALITAS HIDUP PASIEN LANJUT USIA: PERSPEKTIF RAWAT RUMAH
}

\section{PHARMACIST' ROLE POTENCY IN ELDERLY PATIENTS' QUALITY OF LIFE: HOME HEALTH CARE PERSPECTIVE}

\author{
D.A. Perwitasari, A. Muttaqien \\ Fakultas Farmasi, Universitas Ahmad Dahlan, Yogyakarta \\ E-mail : diahperwitasari2003@yahoo.com
}

\section{Abstrak}

Program Home Health Care untuk pasien lanjut usia semakin diminati dan salah satu parameter yang menunjukkan berhasil atau tidaknya program ini adalah peningkatan kualitas hidup pasien. Program Home Health Care merupakan program multidisipliner, dimana peran farmasis juga dibutuhkan di dalamnya. Tujuan dilakukan penelitian ini adalah untuk mengetahui potensi peran farmasis dalam meningkatkan kualitas hidup pasien lanjut usia yang mengikuti program Home Health Care. Penelitian merupakan penelitian deskriptif dengan pengambilan data secara prospektif. Instrumen penelitian adalah kuesioner kualitas hidup World Health Organization Quality of Life yang sudah tersedia dalam bahasa Indonesia. Penelitian ini dilaksanakan selama 13 minggu pada tahun 2009 di rumah pasien lanjut usia yang mengikuti program Home Health Care RSUP Dr. Sardjito Yogyakarta. Data dianalisis secara deskriptif. Sejumlah 7 pasien bersedia berpartisipasi dalam penelitian ini dan rata-rata kualitas hidup mereka adalah rendah $(46,1 \pm 4,4)$. Semua pasien lanjut usia mendapatkan polifarmasi dan ditemukan adanya ketidakpatuhan minum obat dalam penelitian ini. Peran farmasis sangat diperlukan dalam program ini untuk meningkatkan kualitas hidup pasien, terutama dalam meningkatkan kepatuhan pasien, memonitor efek terapi dan efek samping obat yang masuk dalam kategori polifarmasi. Peningkatan dan modifikasi teknik komunikasi, informasi dan edukasi perlu dilakukan oleh farmasis untuk pasien lanjut usia program Home Health Care.

Kata kunci farmasis, kualitas hidup, lanjut usia, home care, WHOQoL 


\section{Abstract}

The Home Health Care program is getting popular as well. One of the outcome measured in this program is patient's quality of life. Home Health Care program is a multidisciplin program, which need the pharmacist role. The aim of this study was to find out the potencial pharmacist role in increasing elderly patients'quality of life participated in Home Health Care program. This study used descriptive design with prospective data sampling. (World Health Organization Quality of Life) We used WHOQoL as the instrument. The study period was conducted for 13 week in 2009 by visiting the patients at their homes. The patients were participated in Home Health Care program of Dr Sardjito hospital, Yogyakarta. Data was descriptively analized. We're recruited seven subjects in this study. In average, their quality of life was low $(46,1 \pm 4,4)$. All of the patients received polypharmacy and were found the patients incompliance in taking the medicines. The role of pharmacist were important in Home Health Care program for elderly patients to increase their quality of life. The pharmacists are supposed to do the drug used monitoring, especially to the elderly patients with polypharmacy. The advance technique for communication, information, and education is suggested to the pharmacist in this program.

Keywords : pharmacist, quality of life, elderly, home care, WHOQoL

\section{PENDAHULUAN}

Sejak tahun 2000, harapan hidup orang Indonesia mencapai usia 70 tahun. Pada 2020, populasi penduduk lanjut usia di Indonesia diproyeksikan mencapai $11,34 \%$ dari total jumlah penduduk (Anonim, 2011). Indonesia antara tahun 1990-2025, menurut data biro sensus Amerika Serikat diperkirakan mengalami pertambahan orang usia lanjut terbesar di dunia, yakni sebesar $414 \%$ (Anonim, 2005).

Menurut definisi WHO, kesehatan tidak hanya bebas dari penyakit atau sakit, tetapi juga kesehatan secara fisik, mental dan sosial. Konsep klinis kualitas hidup pada akhirnya berfokus pada dampak sakit pada kesehatan pasien secara fisik, psikologis dan sosial yang teramati oleh pasien tersebut. Kualitas hidup adalah suatu bangunan multidimensional yang bersifat subjektif, meliputi pengalaman pasien terhadap gejala penyakit dan efek samping pengobatan, sebaik kemampuan fungsional dan kesehatan secara fisik dan psikologis (Anonim, 2005).

Penanganan lebih lanjut di rumah setelah mengalami penataan di rumah sakit sering dipertanyakan pasien dan keluarga. Oleh karena itu, masalah perawatan purna rawat inap di rumah sakit merupakan salah satu tantangan bagi penyelenggara pelayanan kesehatan karena kapasitas rumah sakit sebagai tempat rawat inap masih sangat terbatas, disamping itu biaya pengobatan, perawatan, dan fasilitas penderita relatif 
cukup mahal. Upaya penyelenggaraan rawat rumah (home care) yang dikoordinasikan oleh rumah sakit merupakan upaya yang secara ekonomis layak sebagai alternatif lain dari perawatan di rumah sakit sejauh pertimbangan-pertimbangan medis di lingkungan sosial dan aspek-aspek psikologis dapat terjaga secara cocok dan serasi (Probosuseno, 2000).

Salah satu tujuan dari home care disamping penghematan biaya pemondokan di rumah sakit juga dalam rangka pencegahan sekunder dan pencegahan tersier. Pencegahan sekunder adalah diagnosis dini dan pengobatan segera (early diagnosis and prompt treatment), sedangkan pencegahan tersier adalah rehabilitasi (Friedman, 1998). Pada proses ini diusahakan agar cacat yang diderita tidak menjadi hambatan sehingga individu yang menderita dapat berfungsi optimal secara fisik, mental dan sosial sehingga penderita dapat mempertahankan otonominya selama mungkin. Otonomi di sini lebih ditekankan pada kemampuan aktifitas dasar sehari-hari yaitu kemampuan bergerak, mandi, buang air besar / kecil sendiri dan kegiatan makan (Probosuseno, 2000).

Dari hasil observasi diketahui bahwa RSUP Dr. Sardjito adalah rumah sakit pertama di Indonesia yang memiliki program home care dan ditunjuk sebagai rumah sakit percontohan untuk program home care bagi rumah sakit lainnya. Oleh karena itu RSUP Dr. Sardjito tidak mudah puas dengan apa yang telah dicapai dan ingin terus meningkatkan kualitas pelayanan yang salah satunya adalah menyediakan pelayanan yang dapat memuaskan harapan pelanggannya agar dapat memberikan pelayanan yang dapat sesuai dengan standar. Observasi yang dilakukan di RSUP Dr. Sardjito Yogyakarta berasumsi bahwa masyarakat luas, khususnya yang berada di Daerah Istimewa Yogyakarta telah mengenal rumah sakit ini sebagai rumah sakit daerah yang memiliki kualitas pelayanan prima, sehingga masyarakat akan mempercayakan anggota keluarganya untuk menjalani terapi home care di rumah sakit tersebut. Masyarakat luas beranggapan bahwa program home care mahal sehingga tidak dapat terjangkau oleh masyarakat luas, hanya kelompok tertentu saja yaitu kelompok dengan sosial ekonomi menengah ke atas. Tetapi dengan pelayanan yang tergolong mahal, home care dapat meningkatkan kualitas hidup pasien.

Program home care adalah program multidisipliner, yang artinya diperlukan kolaborasi yang baik dari semua bidang tenaga kesehatan. Salah satu keberhasilan program Home Care dapat dilihat dari peningkatan kualitas hidup pasien. Salah satu yang dibutuhkan disini adalah peran farmasis dalam memonitor penggunaan obat oleh pasien lanjut usia. Penelitian yang dilakukan di Nigeria sebelumnya menunjukkan bahwa peran farmasis dalam pengobatan hipertensi mampu meningkatkan kualitas hidup pasien dan kepatuhan pasien dalam minum obat (Aguwa et al, 2008). Potensi polifarmasi pada pasien lanjut usia cukup besar dengan adanya penurunan fungsi fisik karena proses penuaan. Dalam hal ini, efek terapi, efek samping, kemungkinan interaksi obat dan ketaatan pasien merupakan hal yang harus dipantau oleh farmasis terutama 
ketika pasien ada di rumah (Reily et al, 2012; Venturini et al, 2011).

Tujuan penelitian ini adalah untuk mengetahui potensi peran farmasis dalam rawat rumah pasien lanjut usia terutama untuk meningkatkan kualitas hidup pasien.

\section{METODE PENELITIAN}

Rancangan Penelitian

Penelitian merupakan jenis penelitian deskriptif dengan pengambilan data secara prospektif. Instrumen penelitian adalah kuesioner kualitas hidup WHOQOL (World Health Organization Quality of Life) yang sudah tersedia dalam bahasa Indonesia (Anonim, 2004). Penelitian ini dilaksanakan selama 13 minggu yaitu mulai dari 4 Oktober - 31 Desember 2009 dengan waktu (hari dan jam) yang tidak ditentukan. Sedangkan tempat penelitiannya di rumah pasien lanjut usia yang mengikuti program Home Health Care di RSUP Dr. Sardjito Yogyakarta.

Subjek penelitian ini adalah semua pasien lanjut usia program Home Health Care yang melakukan pengobatan dan perawatan di rumah dibawah pengawasan RSUP Dr. Sardjito Yogyakarta.

\section{Definisi Operasional Variabel}

Pada penelitian ini yang dimaksud dengan kualitas hidup adalah penilaian kualitas hidup pada pasien lanjut usia. Pasien lanjut usia adalah pasien yang berusia 60 tahun ke atas dengan penyakit tunggal.

\section{Analisis Data}

Skor awal kualitas hidup dari instrumen penelitian akan ditransform menjadi skala 0-100 dan akan dikategorikan menjadi skala kategori kualitas hidup sebagai berikut: 0: kematian; 1-55: rendah; 56-79: sedang; 80-99: tinggi dan 100: sempurna.

\section{HASIL DAN PEMBAHASAN}

Hasil penelitian ini menunjukkan bahwa kualitas hidup pasien lanjut usia yang mengikuti program Home Health Care dan menjalani perawatan di RSUP. Dr. Sardjito pada bulan OktoberDesember 2009 rata-rata memiliki kualitas hidup rendah.

Pasien yang bersedia berpartisipasi dalam penelitian ini sejumlah 7 orang, yaitu 2 orang yang berjenis kelamin laki-laki dan 5 orang berjenis kelamin perempuan dengan rata-rata umur responden adalah 80 tahun. Dari 7 pasien tersebut didapatkan hasil bahwa sebanyak 6 pasien memiliki status kualitas hidup rendah dan 1 pasien memiliki status kualitas hidup sedang. Sedangkan rerata kualitas hidup pasien adalah 46,14; SD: 4,43 yang masuk pada range kualitas hidup rendah. Tabel I memperlihatkan gambaran kualitas hidup pasien pada masing-masing dimensi. 
Tabel I. Rerata dan simpangan baku kualitas hidup pasien geriatri dengan home health care di RSUP Dr. Sardjito, periode Oktober - Desember 2009

\begin{tabular}{|l|c|c|}
\hline \multicolumn{1}{|c|}{ Kategori } & Rerata & Simpangan baku \\
\hline Status kualitas hidup & 46,1 & 6,3 \\
Dimensi kualitas hidup & & \\
Kesehatan Fisik & 43 & 14 \\
Kesehatan Mental & 50 & 10 \\
Hubungan Sosial & 34 & 12 \\
Lingkungan & 61,9 & 9,2 \\
\hline
\end{tabular}

Adanya beberapa macam penyakit dapat menurunkan kualitas hidup pasien terutama pada pasien-pasien lanjut usia karena kemampuan rehabilitasi tubuh mereka tidak sebaik orang dewasa. Oleh karena itu dengan menjalani Home Health Care pada pasien lanjut usia, diharapkan kualitas hidup mereka tidak semakin menurun. Dari hasil penelitian ini, kita tidak dapat mengetahui apakah kualitas hidup pasien meningkat atau menurun setelah menjalani program Home Health Care. Namun setidaknya terdapat gambaran bahwa dengan program Home Health Care kualitas hidup pasien masih perlu ditingkatkan. Peningkatan kualitas hidup pasien lanjut usia ini dapat dilakukan dengan peningkatan kualitas pelayanan program Home Health Care.

Hasil penelitian ini konsisten dengan hasil penelitian dari Akvardar et al (2006), yang menggunakan kuestioner WHOQOL BREF untuk mengukur kualitas hidup dari pasien psikiatri, diabetes dan orang sehat. Dalam penelitiannya menyatakan bahwa kualitas hidup dipengaruhi oleh kesehatan mental, penyakit dan kebiasaan buruk (merokok, minum alkohol). Seperti yang diperkirakan, orang sehat memiliki kualitas hidup yang paling baik di antara kedua pasien yang dibandingkan. Selanjutnya adalah pasien dengan penyakit diabetes memiliki kualitas hidup di atas pasien psikiatri. Diabetes dan psikiatri juga merupakan penyakit yang insidensinya cukup tinggi pada pasien lanjut usia.

Menurut WHO (Anonim, 2004), kesehatan fisik itu dipengaruhi oleh hal berikut ini: energi dan kelelahan, mobilitas, penderitaan dan kegelisahan, tidur dan istirahat, kapasitas pekerjaan. Kesehatan mental dipengaruhi oleh gambaran dan penampilan psikologis yang meliputi: perasaan positif dan negatif, kepercayaan diri, agama, dan kemampuan untuk berkonsentrasi. Hubungan sosial dinilai berdasarkan hubungan sosial dan hubungan pribadi yang meliputi: dukungan sosial dan aktivitas seksual. Lingkungan dipengaruhi oleh kebebasan, kepedulian kesehatan dan sosial, lingkungan rumah, keikutsertaan pada aktivitas rekreasi, serta transportasi. Dengan demikian dimensi kualitas hidup tersebut saling berkaitan satu sama lain untuk mendapatkan satu kualitas hidup pasien.

Dari observasi yang dilakukan peneliti ditemukan bahwa sejumlah 2 pasien mempunyai lebih dari 10 jenis 
obat yang harus dikonsumsi rutin, sedangkan 5 pasien rata-rata mempunyai 2-5 jenis obat. Penyakit kardiovaskuler menjadi dominasi dalam penelitian ini yang menyebabkan pasien mendapatkan banyak obat. Pasien juga kurang patuh terhadap frekuensi penggunaan obat. Hal ini dapat menjadi penyebab kurang berhasilnya terapi yang dilakukan dan kemungkinan akan memperparah kondisi pasien yang bersangkutan. Hasil observasi ini menunjukkan bahwa peran farmasis akan sangat dibutuhkan dalam hal monitoring penggunaan obat oleh pasien. Adanya polifarmasi tersebut memunculkan kemungkinan interaksi obat-obat dan obat-makanan yang cukup besar (Venturini et al, 2011). Hasil penelitian ini konsisten dengan penelitian terbaru yang dilakukan di Jepang, bahwa farmasis mempunyai banyak peran dalam pengobatan pasien lanjut usia seperti menangani permasalahan penggunaan obat yang kurang atau berlebihan, permasalahan dosis, peracikan obat, edukasi terhadap pasien lanjut usia dan tenaga kesehatan lain (Reily et al, 2012)

Secara tidak langsung, farmasis juga berperan dalam meningkatkan kualitas hidup pasien (Bentley et al, 1998). Munculnya ketidakpatuhan pasien dalam minum obat, menimbulkan tidak tercapainya tujuan terapi. Pada beberapa obat psikiatri, adanya ketidakpatuhan minum obat akan memunculkan efek withdrawl yang mengakibatkan kondisi pasien tidak semakin baik. Munculnya kondisi tersebut akan mengakibatkan turunnya kualitas hidup pasien. Farmasis perlu merencanakan metode untuk meningkatkan kepatuhan pasien lanjut usia minum obat, terutama untuk pasien yang mengikuti program Home Health Care. Peneliti menyarankan adanya peningkatan dan modifikasi teknik komunikasi, edukasi dan informasi untuk pasien lanjut usia, sehingga pesan yang disampaikan lebih dapat diterima.

Terbatasnya jumlah responden dalam penelitian ini merupakan salah satu keterbatasan penelitian ini, sehingga perlu dilakukan penelitian selanjutnya dengan jumlah responden yang lebih besar dengan rancangan action research untuk mengetahui peran farmasis dalam meningkatkan kualitas hidup pasien lanjut usia yang mengikuti program Home Health Care.

\section{KESIMPULAN}

Rata-rata kualitas hidup pasien lanjut usia program Home Health Care di RSUP Dr Sardjito Yogyakarta adalah $46,1 \pm 4,4$, termasuk dalam kategori kualitas hidup rendah. Peran farmasis sangat diperlukan dalam program ini untuk meningkatkan kualitas hidup pasien, terutama dalam meningkatkan kepatuhan pasien, memonitor efek terapi dan efek samping obat yang masuk dalam kategori polifarmasi. Peningkatan dan modifikasi teknik komunikasi, informasi dan edukasi perlu dilakukan oleh farmasis untuk pasien lanjut usia yang mengikuti program Home Health Care.

\section{DAFTAR PUSTAKA}

Aguwa, C.N., Ukwe, C.V., Ekwunife, O.I., 2008., Effect of pharmaceutical care programme on blood pressure and quality of life in a Nigerian pharmacy. 
Pharm World Sci ;30(1):107-10. Epub 2007 Aug 17.

Akvardar, Y., Akdede, B.B., Ozerdem, A., Eser, E., Topkaya, S., Alptekin, K., 2006., Assessment of quality of life with the WHOQOL-BREF in a group of Turkish psychiatric patients compared with diabetic and healthy subjects., Psychiatry Clin Neurosci. 60(6):693-9.

Anonim, 2004, "The World Health Organization Quality of Life (WHOQOL)-BREF",http://www. who.int/substance abuse/research _tools/en/english_whoqol.pdf. diakses tanggal $1 \overline{5}$ Agustus 2009.

Anonim, 2005, Tua Pasti Tiba, Ethical Digest, No 19 Tahun III September 2005. Jakarta.

Anonim, 2011, Optimalkan Pemberdayaan Lansia Melalui Homecare, http://

http://www.kemensos.org/infocar e/index.php?option $=$ com content $\underline{\text { \&view }=\text { article\&id }=157 \text { :optimalk }}$ an-pemberdayaan-lansia-lewat-ho me-care\&catid $=51$ :pelayanan-pri $\underline{\text { ma\&Itemid }=66}$, diakses tanggal 18 Maret 2012

Bentley, J.P., Smith, M.C., Banahan, B.F., Frate, D.A., Parks, B.R.,
1998., Quality of life assessment by community pharmacists: an exploratory study. Qual Life Res ;7(2):175-86.

Friedman, M.M., 1998, Family Nursing, Research. Theory and Practice, Fourth edition, Applenton \& Lange, Stamford.

Probosuseno, 2000. "Program Rawat Rumah (Home Care) berbasis Rumah Sakit Bagi penderita Usia Lanjut". Makalah dipresentasikan pada rapat kerja KOPAPDI, juli 2000. Surabaya.

Reilly., T., Barile, D., Reuben, S., 2012., Role of the Pharmacist on a General Medicine Acute Care for the Elderly Unit. Am J Geriatr Pharmacother. 2012 Feb 29. [Epub ahead of print]

Venturini, C.D., Engroff, P., Ely, L.S., Zago, L.F., Schroeter, G., Gomes, I., De Carli, G.A., Morrone, F.B., 2011.,Gender differences, polypharmacy, and potential pharmacological interactions in the elderly. Clinics (Sao Paulo) ;66(11):1867-72. 